\title{
Progressive clinical evaluation tools based on the Quality and Safety Education in Nursing competencies
}

\author{
Amanda S. Eymard, Angele Davis, Rebecca Lyons \\ Nicholls State University, Thibodaux, USA. \\ Correspondence: Amanda S. Eymard. Address: Nicholls State University, P.O. Box 2143, Thibodaux, LA 70310, USA. \\ Email: Amanda.eymard@nicholls.edu \\ Received: July 17, 2013 \\ Accepted: July 28, 2013 \\ Online Published: October 10, 2013 \\ DOI : $10.5430 /$ jnep.v4n2p116 \\ URL: http://dx.doi.org/10.5430/jnep.v4n2p116
}

\begin{abstract}
Despite integrating innovative teaching strategies in the classroom, nurse educators continue to struggle with evaluating students' ability to provide safe, competent patient-centered care in the clinical setting. Members of the baccalaureate research and evaluation committee developed a set of Clinical Performance Evaluation Tools incorporating the knowledge, skills, and attitudes for each of the Quality and Safety Education in Nursing (QSEN) competencies. Remediation strategies for each course were addressed with a separate tool, the Clinical Performance Remediation (CPR) Tool. The tools also include a section regarding professionalism. This manuscript describes the process and outcome for creating an evaluation tool that blended an effective combination of QSEN's core competencies, the Essentials of Baccalaureate Education for Professional Nursing Practice, and the Nicholls State University baccalaureate program's conceptual model. The tools were piloted spring of 2012. Nursing programs can enhance evaluation of students' clinical performance by incorporating the newly developed clinical performance evaluation tools.
\end{abstract}

\section{Key words}

Clinical, Evaluation, Quality and Safety Education in Nursing, Professionalism, Remediation

\section{Introduction}

Designing innovative teaching strategies while ensuring an educational experience which results in safe nursing practice is a challenge for all faculty members involved with baccalaureate programs. Nurse educators continue to struggle with methods for determining outcomes, constantly looking for ways to better evaluate students' abilities to evolve into professional nurses who will provide safe, competent, patient-centered care in the clinical setting. There is a disconnect between the evaluation of clinical practice, best evaluation practices as defined by the American Association of Colleges for Nursing's Essentials of Baccalaureate Education for Professional Nursing Practice (2008), and evaluation procedures and tools used by our baccalaureate program's newly revised conceptual model (see Figure 1), which calls for rigorous revision of current clinical evaluation tools.

The program's Research and Evaluation Committee was recently charged with leading the revision of these clinical evaluation tools. This article delineates the tools' development process (see Figure 2), necessary remediation strategies, and the results of an informal pilot study of the tools. It also gives an administrative perspective regarding the tools that the committee developed. Finally, it offers an assessment of the newly developed tools, concluding that they provide a clear, 
concise evaluation strategy that will assist faculty in guiding and mentoring student nurses so that they may be better poised to succeed in the clinical setting.

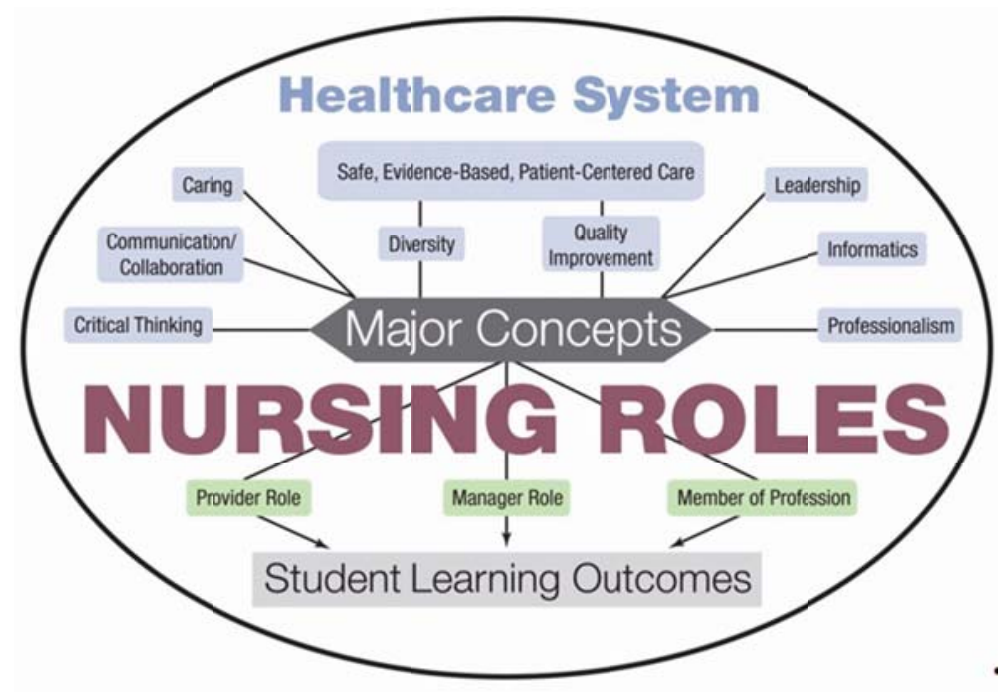

Figure 1. Nicholls State University BSN Program Conceptual Model

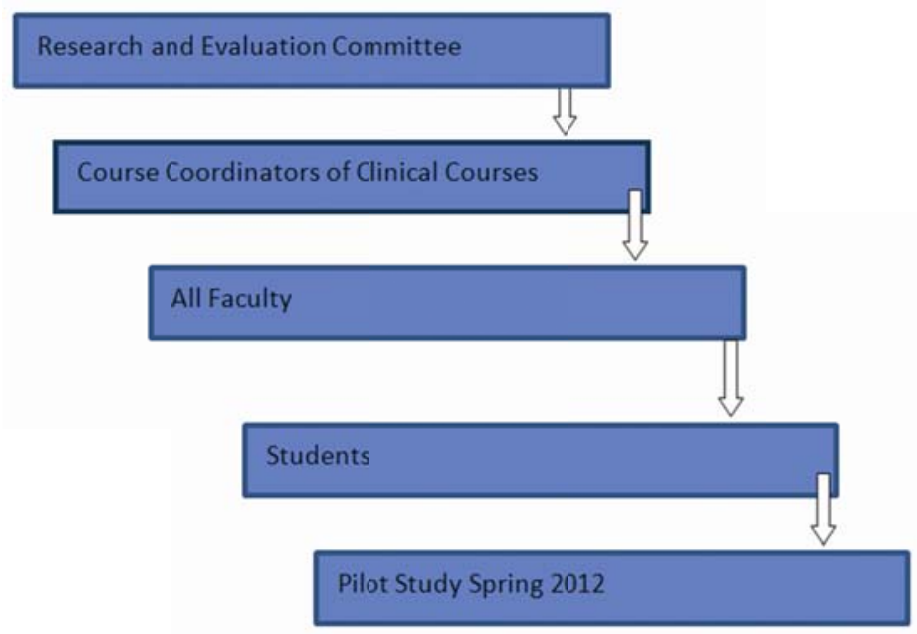

Figure 2. Visual Depiction of Progressive Clinical Evaluation Tool Development Process

\section{Methodology}

\subsection{Development and description of the tools}

Both department head and faculty agreed that the current clinical evaluation tools were not user friendly, were outdated and lengthy, and were not relevant to student outcomes. To complicate matters, the department had recently undergone a major curriculum revision in preparation for accreditation. To address current needs, the department head charged the Research and Evaluation (R\&E) Committee of the Nursing Department with the task of developing clinical evaluation tools that were clear, concise, and progressive throughout the nursing program. The revision process began with the nine R\&E Committee members meeting to formulate a plan. To establish the foundation for the Clinical Progressive Evaluation Tools (CPETs), committee members reviewed vital information, including The Essentials of Baccalaureate Education for 
Professional Nursing Practice, the Commission on Collegiate Nursing Education's Standards for Accreditation for Baccalaureate and Graduate Nursing Degree Programs (2009), and the QSEN Quality and Safety Competencies. The committee realized the importance of linking clinical evaluation tools to the program's conceptual model and newly revised curriculum, since both the conceptual model and curriculum are informed by the aforementioned standards and competencies.

Committee members then began the task of locating existing tools, to report findings back to the committee. The R\&E Committee began by researching those clinical evaluation tools used by nursing programs at other schools. One R\&E member proposed that the committee examine the assessment tools used by University of Portland, and suggested modeling tools on them. Walsh ${ }^{[1]}$ provides much insight regarding the inclusion of the QSEN Quality and Safety Competencies, as articulated by Cronenwett ${ }^{[2]}$, in clinical evaluation tools, and contributes to the discussion of the CPETs. After deliberation and an official vote, the committee agreed that the Portland model was a good match, and decided to adapt the tools, particularly since they included the QSEN competencies. The committee had analyzed and assessed a variety of evaluative tools used by other schools of nursing. The University of Portland ${ }^{[3]}$ tools were, by contrast, found by R\&E members to be a perfect fit for the program's needs, for they were extremely useful in establishing clear guidelines.

R\&E members were then assigned to create tools for individual clinical nursing courses, and each committee member met and collaborated with a clinical course coordinator to develop clinical evaluation tools for each course. After this initial meeting, all faculty from all levels of the program were invited into the discussion, for the further development of the tools. Ten course coordinators were involved, as part of the twenty-seven faculty member evaluation team. During the pilot study, all 358 clinical students who used the tools were invited to comment on the tools; twenty students opted to give feedback. All clinical faculty and all course coordinators, a total of 25, also provided feedback. No control group was used. Students were asked if the tools were clear, relevant, and reflective of necessary elements in the clinical setting evaluation process.

Both the CPETs and remediation tools were piloted in the spring of 2012 in all clinical nursing courses, and the development process had stimulated much discussion among committee members, faculty members, students, and administrators, as it provided an opportunity for faculty and students to discuss in depth The Essentials of Baccalaureate Education, other Commission on Collegiate Nursing Education (CCNE) standards, and the QSEN Competencies. Significantly, since both faculty and students were engaged in the change process all involved were more receptive to the changes because they had a sense of buy-in or ownership.

Throughout this process, as the committee developed its version of CPETs, it incorporated the knowledge, skills, and attitudes (KSAs) ${ }^{[4]}$ that met each of the QSEN competencies. In addition to incorporating KSAs that met QSEN competencies, the faculty felt strongly about including a professionalism section within the tools being a major focus of the program is professionalism. Because each clinical course is unique, it was necessary to describe the expectation of progression of the CPETs throughout the curriculum and their alignment with each level's outcomes. Therefore, eight course/level specific tools were developed demonstrating progression throughout the program. R\&E members developed the tools for all eight courses, with the input from faculty and course coordinators. Remediation strategies for each course were addressed with a separate tool, the Clinical Performance Remediation (CPR) Tool. The committee chose the CPETs because they are utilized in all clinical nursing courses, and the tools include guidelines, composed of four distinct sections, for use.

\section{Clinical progressive evaluation tools}

Clinical Progressive Evaluation Tools (CPETs) are a set of tools utilized in all clinical nursing courses, and include guidelines for use, which are composed of four distinct sections. An example of a CPET is included in Figure 3. The guidelines provide clear and consistent expectations for faculty and students, and they included a thorough grade description for each possible score (see Figure 4). The first section provides the faculty, preceptor, and student with concise instructions for completion, including directions for scoring and timing of form completion. At minimum, the tools are designed to be used twice, at mid-semester and at the end of the semester. At both evaluation points, the student 
and faculty/preceptor completed separate CPET evaluations using the same CPET developed for that clinical nursing course. Additionally, the tools' requiring student to complete a self-evaluation engaged them in reflection and allowed them to realize their areas of strength, as well as those needing improvement. Another identified strength of these tools was that while previous evaluation tools were limited to two scores (satisfactory and unsatisfactory), these allowed for an additional scoring option between satisfactory and unsatisfactory — the score of "needs improvement" (NI). The faculty members exercised the discretion to complete evaluations when deemed necessary; inclusion of faculty autonomy and early intervention in the process provided students with a timely and objective evaluation of their performances. This provided the best opportunity for students to succeed in the clinical course, as the NI score made possible a broader and more constructive assessment of student outcomes.

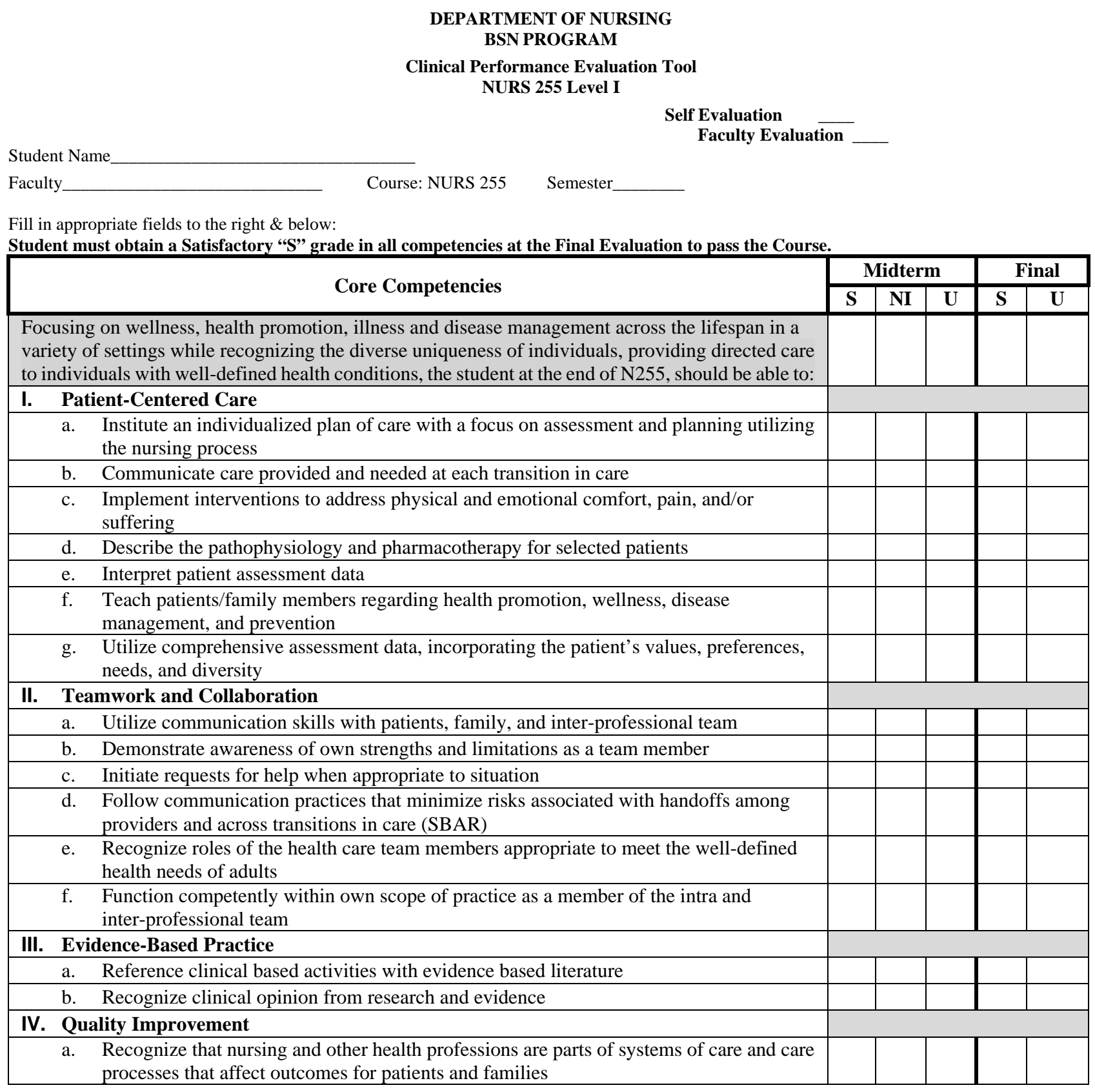

Figure 3. Sample Clinical Performance (CPR) Evaluation Tool- Level 1 
The second section of the guidelines provided a description of core competencies. The tools contain seven core competency associated statements based on program, level, and course outcomes. The QSEN competencies inform six of these seven, with professionalism the seventh, and the associated statements under each of the core competencies are comprised of QSEN's ${ }^{[4]}$ KSA statements and course outcomes (The progressive competency statements for the QSEN competencies and professionalism are based on Bloom's ${ }^{[5]}$ taxonomy, to ensure that each tool is appropriate for the course level). While the QSEN competencies allow for a progressive evaluation, those for professionalism are generally static through all levels, with some infusion of progressive evaluation. The static elements include concepts such as core professional values; compliance with Nurse Practice Acts; acceptance of constructive criticism; and development of a plan of action for improvement, attitude, attendance, punctuality, and policy/procedure. The progressive elements rated under professionalism include preparation, accountability, responsibility, and level of engagement in self-evaluation.

The last two sections of the guidelines provide clear expectations regarding score assignment. Each of the three scores contains clearly defined descriptions that allow students and faculty to easily determine an appropriate score. The two important factors which swayed the committee in favor of the tools were that they do not delineate how many times a student may or may not complete a task, focusing instead on providing a guide to achieving high-quality performance, and that they allow for consistency in evaluation because they are standardized.

\section{Remediation strategies}

Since no student can be successful in the course if he/she is unable to achieve a satisfactory score during the final clinical evaluation, initiation of remediation using the CPR tool (for a score of NI) is at the discretion of the faculty member, in remediating both unprofessional behavior and unsatisfactory clinical performance. This came about because faculty voiced concern that there was a lack of a formalized, consistent remediation plan. The CPR tool was developed to provide an objective, clear assessment of clinical performance through daily evaluation in the area(s) needing remediation. According to the guidelines, faculty members are required to initiate the CPR tool when an unsatisfactory score for any core competency statement is earned at mid-clinical. Daily follow-up provides an individualized opportunity for faculty/student conferences and clear documentation regarding progress.

\section{Grade Descriptions}

\begin{tabular}{|c|c|}
\hline $\begin{array}{l}\text { A grade of "S" } \\
\text { means the student: }\end{array}$ & $\begin{array}{l}\text { - } \quad \text { Functions satisfactorily with minimum guidance in the clinical situation. } \\
\text { - } \quad \text { Demonstrates accurate and appropriate knowledge and integrates knowledge with skills } \\
\text { and attitudes. } \\
\text { - } \quad \text { Engages consistently in self direction in approach to learning. } \\
\text { - } \quad \text { Provides evidence of preparation for all clinical learning experiences. } \\
\text { - } \quad \text { Identifies own learning needs and seeks appropriate assistance. } \\
\text { - } \quad \text { Demonstrates continued improvement during the semester. } \\
\text { - } \quad \text { Uses nursing process and applies scientific rationale. }\end{array}$ \\
\hline $\begin{array}{l}\text { A grade of "NI” } \\
\text { means the student: }\end{array}$ & $\begin{array}{l}\text { - } \\
\text { - } \quad \text { Dunctions safely with moderate amount of guidance in the clinical situation. } \\
\text { knowledge with skills. } \\
\text { - } \quad \text { Requires some direction in recognizing and utilizing learning opportunities. }\end{array}$ \\
\hline $\begin{array}{l}\text { A grade of "U” } \\
\text { means the student: }\end{array}$ & $\begin{array}{l}\text { - } \\
\text { - } \\
\text { - } \\
\text { - } \text { Dequires intense guidance for the performance of activities at a safe level. } \\
\text { assistance in integrating knowledge and skills. } \\
\text { - } \quad \text { Requires frequent and detailed instructions regarding learning opportunities and is often } \\
\text { unable to utilize them. } \\
\text { - } \quad \text { Is often unprepared and has limited insight into own behavior. } \\
\text { - } \quad \text { Is unable to identify own learning needs and neglects to seek appropriate assistance. } \\
\text { - } \quad \text { Breaches in professional or ethical conduct such as falsification of records and failure to } \\
\text { maintain confidentiality. }\end{array}$ \\
\hline
\end{tabular}

Figure 4. Grade Description for all Possible Scores 


\subsection{I mplementation of the tools}

Faculty and students were oriented to the tools prior to the pilot study. The Research and Evaluation Committee piloted the tools throughout all clinical nursing courses spring of 2012. The pilot study utilizing a survey format was conducted via email and face to face with faculty and students. Faculty and students were strongly encouraged to provide feedback regarding the tools throughout the semester. Faculty and students were reminded during mid-term and final clinical evaluations to provide feedback regarding the tools.

The tools were piloted in all eight clinical nursing courses during the spring of 2012. This included piloting the tool with 358 clinical nursing students at all three levels within the nursing program. All 25 clinical nursing faculty members were involved in the pilot study. Each faculty member utilized the CPET in every nursing course which included a clinical component. All 358 students in the pilot study completed a self-evaluation utilizing the newly developed CPET. Students completed self-evaluations at mid-semester and completion of semester utilizing the same CPET utilized by faculty for evaluations. This gives the students the opportunity to reflect and critically evaluate themselves in the clinical setting. After the students complete their self-evaluations, they meet with the faculty members to discuss their self-evaluations and the faculty evaluations.

\section{Findings of the pilot study}

\subsection{Faculty and students}

Throughout the semester during which the pilot study was carried out, an informal survey was conducted via email, and face to face with faculty and students, in which they were strongly encouraged to provide feedback regarding the tools. They were also reminded during mid-term and final clinical evaluations to provide feedback regarding the tools. Initially, the committee noted some resistance by faculty, mainly in that some faculty members expressed a high comfort level and sense of familiarity with the old tools and a general dislike for change, likely due to what Stuart ${ }^{[6]}$ and Billings and Halstead ${ }^{[7,8]}$ characterize as feelings of uncertainty. Initial comments by faculty included a request to not include quality improvement in clinical experience evaluations, as some faculty members stated they were unfamiliar with quality improvement initiatives in the clinical settings. Some expressed a belief that students would not be able to incorporate the KSAs included in the tools. However, after discussion (and as the expectations of QSEN were made clearer), faculty in the program became more comfortable with a shift in teaching and evaluation strategies in the clinical setting. After the pilot study, faculty stated that the new tools were effective and resulted in the desired student outcomes. One faculty member commented on the intuitive nature of the tools, stating that they were "easy to use." Several faculty members commented that the tools provided clear instructions, making the process of objectively evaluating students easier and more efficient.

Initially, students were in agreement about the necessity to revise the previously used clinical evaluation tools. Many students expressed excitement concerning the older clinical evaluation tools being revised and updated. Comments included appreciation for streamlining the tools and making them seem relevant and useful. Students expressed appreciation for the clarity of the tools. One student stated, "It is easier to understand what I'm being evaluated on." Another commented, "I know exactly what is being asked of me."

\subsection{The administrative perspective}

While administration agreed that the value of clarity in clinical performance evaluation tools cannot be underestimated (for both faculty and students), they felt that any level or type of evaluative process must be linked or aligned with the expected outcomes of the experience, the course, the level, and the mission of the program. If mal-alignment exists and rogue documents are created in each clinical course by perhaps four or five course faculty in six different clinical courses, not only is inter-rater reliability impossible to establish, but critically, the program's mission/conceptual model/essentials/ standards will likely be lost or obfuscated. From an administrative perspective, this alignment must exist to meet accreditation standards, reflecting that the program is a unified one: Faculty ultimately and intimately need to know, 
understand, and value the expected student learning outcomes and the expected premise in which the teaching is to occur, and administration must ensure this is occurring.

A critical element in the clinical evaluation process is student remediation, and importantly, from an administrator's view, the documentation that accompanies the issues and remediation plan. The CPR tool provided a clear venue for both the student and the faculty when student performance requires improvement. Historically, faculty often struggle with timely, objective documentation when a student is performing poorly or failing clinically. Also, faculty often experience anger, defensive behavior, and frustration with hierarchy, and some come to feel self-doubt about their choice of career in nursing education. The process is an emotional drain. Administration expressed that the new CPR tool has provided a venue to address these issues. After all, sound decisions and fair and reasonable evaluation of students in the clinical setting supports the on-going transformation in the culture of nursing education and practice. Schools of nursing are expected to teach students to be patient-centered. To do so, educators should be student-centered. If this is not the case, again, the mal-alignment and the ever-widening gap in nursing education and practice will continue. Getting all stakeholders present in the conversation and hearing what is being said is necessary and can be done through effective administrative leadership.

\section{Conclusions}

Fair and consistent evaluation of clinical performance of nursing students continues to be a tremendous challenge to nurse educators. Our program's newly developed CPETs encompass The Essentials of Baccalaureate Education, CCNE Standards, and the QSEN Competencies. They provide a clear, concise, meaningful evaluation strategy to assist faculty in promoting student success, allowing for faculty and students to articulate and agree on clear expectations, leading to consistency among all clinical faculty and across the entire nursing program. The tools offer clarity, consistency, and an objective evaluation in an area of nursing education that is sometimes viewed as inconsistent, subjective, and unclear. In the future, the authors would like to conduct further studies regarding the CPETs and provide more descriptive and inferential results to support the effectiveness of the tools.

\section{References}

[1] Walsh, T., Jairath, N., Paterson, M., \& Grandjean, C. Quality and safety for nurses clinical evaluation tool. Nursing Education. 2010; 49(9): 517-22. PMid:20672776 http://dx.doi.org/10.3928/01484834-20100630-06

[2] Cronenwett, L., Sherwood, G., Barnsteiner, J., Disch, J., Johnson, J., Mitchell, P., et al. Quality and safety education for nurses. Nursing Outlook. 2007; 55: 122-131. PMid:17524799 http://dx.doi.org/10.1016/j.outlook.2007.02.006

[3] University of Portland. School of nursing: Clinical learning and evaluation tools. 2012. Available from: http://nursing.up.edu/default.aspx?cid=7732\&pid=2959

[4] Quality and Safety in Education for Nurses. Competency KSA’s (Pre-licensure). 2012. Available from: http://www.qsen.org/ksas_prelicensure.php

[5] Bloom, B., Krathwohl, D., \& Masia, B. Taxonomy of educational objectives: The classification of educational goals. New York: Longman. 1984.

[6] Stuart, G. Principles and practice of psychiatric nursing. (9th ed.) St. Louis: Mosby Elsevier. 2009.

[7] Billings, D. \& Halstead, J. Teaching in nursing. (4th ed.). St. Louis: Elsevier. 2012.

[8] Bonnel, W. Clinical performance evaluation. In D. Billings \& J. Halstead (Eds.), Teaching in nursing education. 2012: 485-502. St. Louis: Elsevier 